\title{
MEMÓRIA E IDENTIDADE NA LITERATURA DE TRADIÇÃO ORAL
}

\author{
Keutre Gláudia da Conceição Soares Bezerra \\ Doutorando em Letras \\ Programa de Pós Graduação em Letras - PPGL \\ Universidade do Estado do Rio Grande do Norte (UERN) \\ Maria Lúcia Pessoa Sampaio \\ PhD Université Paris 8, France, Doutora em Educação \\ Universidade do Estado do Rio Grande do Norte (UERN) \\ Lílian de Oliveira Rodrigues \\ Doutora em Letras \\ Universidade do Estado do Rio Grande do Norte (UERN)
}

\section{RESUMO}

Este trabalho tem como foco a literatura oral, com o objetivo de compreender a relação que se estabelece no cotidiano dos contadores de histórias, entre a memória, as narrativas, e a construção da identidade. Trata-se de parte da dissertação de mestrado "No fantástico palco da memória: histórias de Trancoso e construção da identidade na cultura popular", defendida no curso de Mestrado Acadêmico em Letras da Universidade do Estado do Rio Grande do Norte. A realização do estudo foi pautada na metodologia da história oral e fundamentada numa revisão bibliográfica das categorias memória, narrativa e identidade.

Palavras-chave: memória, identidade, literatura oral.

\section{ABSTRACT}

INTRODUÇÃO
This paper focuses on oral literature, aiming to understand the relationship established in the daily storytelling, between memory, narratives, and the construction of identity. This is part of the master's thesis "No fantástico palco da memória: histórias de trancoso e construção da identidade na cultura popular" (On the fantastic stage of memory: Trancoso's stories and identity construction in popular culture), defended in the Master's Degree in Academic Studies at the State University of Rio Grande do Norte. The study was based on the methodology of oral history and based on a bibliographic review of the categories memory, narrative and identity.

Keywords: memory, identity, oral literature. 
O objetivo deste trabalho é analisar as histórias da literatura oral, conhecidas no interior do Rio Grande do Norte como "histórias de Trancoso", procurando entender a relação entre as narrativas, a memória e a construção da identidade cultural a partir das histórias contadas por uma narradora. O trabalho faz parte da dissertação de mestrado intitulada "No fantástico palco da memória: histórias de Trancoso e construção da identidade na cultura popular", defendida no Mestrado Acadêmico em Letras da Universidade do Estado do Rio Grande do Norte.

A constituição da literatura oral enquanto objeto de estudo nos leva a trilhar um caminho metodológico que possibilite a análise de dados obtidos através da oralidade. Desde a escolha da temática a ser pesquisada, precisamos de uma metodologia que possibilite um tratamento condizente com as características do objeto de estudo.

Por se tratar de um tema com base teórica nos estudos da memória e da identidade, e dada as peculiaridades do corpus, faz-se necessário uma metodologia qualitativa de investigação, a partir da qual possamos analisar os dados à luz do método da história oral. Para tanto, vale esclarecer que "o estudo da oralidade veio sendo ensaiado a partir da antropologia, no âmbito da pesquisa dos processos de transmissão das tradições orais" (LOZANO, 2006, p. 15). No entanto, Lozano (2006) mostra que o estudo da oralidade ultrapassou o campo da antropologia.

Embora saibamos que "desde o século passado, a antropologia, a história, a sociologia, o jornalismo, a psicologia, entre outras áreas [...], tem se ocupado de depoimentos, testemunhos e entrevistas como forma de registro e análises sociais" (BOM MEIHY, 1998, p. 35), somente no século XX, a história oral se firma como metodologia nas ciências sociais.

Visando a concretude do trabalho, utilizamos como técnica a gravação em áudio. A técnica da entrevista com gravador "[...] permite apanhar com fidelidade os monólogos dos informantes, ou o diálogo entre informante e pesquisador, guardando-o em seguida por longo tempo. [...]" (QUEIROZ, 
1991, p. 56). Além disso, "a entrevista da história oral permite também recuperar aquilo que não encontramos em documento de outra natureza: acontecimentos pouco esclarecidos ou nunca evocados, experiências pessoais, impressões particulares, etc. [...]" (ALBERTI, 2005, p. 22).

Salientamos que foi realizada(os) entrevistas/depoimentos com uma contadora de histórias, identificada apenas como contadora através da letra C, visando assim ao anonimato das informações pessoais. Para este trabalho, apresentamos os resultados da análise de uma narrativa caracterizada como conto de encantamento.

\section{MEMÓRIA E IDENTIDADE}

A memória representa uma função social muito importante para a formação da cultura de uma sociedade, em especial para a cultura popular, que tem seu veículo de transmissão basicamente formado na oralidade, o que requer um maior trabalho de memorização, pois só quem tem uma boa memória é capaz de adquirir um repertório significativo dos saberes dessa cultura.

Sobre o estudo da memória, encontramos alguns teóricos que refletem acerca dos aspectos da memória, entre eles o trabalho de Ecléa Bosi (2007), procurando mostrar a realidade da sociedade paulista numa determinada época, a partir da história de vida de um grupo de moradores, que em sua velhice carregam todo um conhecimento histórico da sociedade na qual vivem e da qual adquiriram as experiências vividas no seio dos grupos sociais com os quais conviveram. Conhecimento transmitidos a partir da experiência social acumulada desde a infância. Esse aspecto é abordado por Bosi, quando enfoca que

a criança recebe do passado não só os dados da história escrita; mergulha suas raízes na história vivida, ou melhor, sobrevivida, das pessoas de idade que tomaram parte na sua 
socialização. Sem esta haveria penas uma competência obscura para lidar com os dados do passado, mas não a memória (2007, p. 73).

A autora mostra a chegada desses dados a nós através da memória, e revelam muitas vezes um lado da história de uma comunidade que não está escrito. Esses dados estão na memória de quem viveu os acontecimentos sociais, mas não escreveu sua versão dos fatos, que são repassados aos mais novos, principalmente pelos avós, pois são eles os introdutores da criança em um mundo situado no limiar do passado com o presente, pois tanto a criança quanto o velho não estão preocupados com o presente como os adultos.

Encontramos uma discussão interessante sobre a memória e sua função na sociedade no pensamento de Pollak (1989), que tenta mostrar o enquadramento da memória na vida social, a partir do pressuposto de que a formação de nossas lembranças vêm da convivência em um determinado grupo social.

Assim, os elementos das histórias de Trancoso são configurados no convívio social, o que nos leva a discussão que Halbwachs levanta a respeito da existência de uma memória coletiva. Para o autor, "nossas lembranças permanecem coletivas e nos são lembradas por outros, ainda que se trate de eventos em que somente nós estivemos envolvidos e objetos que somente nós vimos. Isso acontece porque jamais estamos sós. [...]" (2006, p. 30).

As lembranças não são algo estanque que surge do passado, ao contrário, elas estão em movimento com o presente, permeando o viver em sociedade, e são, por isso, indispensáveis para a vida social. Como lembra Bosi, "Na maior parte das vezes, lembrar não é reviver, mas refazer, reconstruir, repensar, com imagens e ideias de hoje, as experiências do passado. A memória não é sonho, é trabalho" (2007, p. 55). Esse trabalho que a memória faz com as lembranças proporciona 
ao sujeito a construção de uma identidade cultural, pois permite a reflexão sobre si e sobre o seu contexto social.

Meneses postula que "o conceito de identidade implica semelhança a si próprio, formulada como condição de vida psíquica e social” (2006, p. 182). E se aproximaria muito mais do reconhecimento, da busca por uma atitude conservadora, fato este que leva o autor a afirmar: "o suporte fundamental da identidade é a memória", pois pela memória o homem se esforça por manter vivo o passado de sua coletividade; desse passado aflora seu sentimento de pertencimento a uma comunidade.

No caso das narrativas, esse suporte para a construção da identidade provém do fato de que o contador de histórias é alguém que se destaca na comunidade pela capacidade de reter as histórias na memória e preservar aspectos importantes de sua sociedade, mantidos através da oralidade, como mostra Xidieh, ao dizer que "a literatura oral nunca é gratuita como pode ser a literatura culta. Ela tem uma função, ou mais de uma: preservar as crenças, os valores, os comportamentos dos grupos rústicos que as produziram" (1993, p. 19).

Estas narrativas são entendidas como a arte de narrar, e ao mesmo tempo criar e recriar o enredo das histórias, que sendo contadas por um indivíduo em particular, agregam elementos do social. Como afirma Candido, "os elementos individuais adquirem significado social na medida em que as pessoas correspondem a necessidades coletivas; e estas, agindo, permitem por sua vez que os indivíduos possam exprimir-se, encontrando repercussão no grupo" (2006, p. 35).

Pollak também aborda a questão da relação entre identidade e memória, afirmando que "a memória é um fenômeno construído social e individualmente, quando se trata da memória herdada, podemos também dizer que há uma ligação fenomenológica muito estreita entre a memória e o 
sentimento de identidade." (1992, p. 05). O autor reforça a ênfase na identidade como fenômeno construído socioculturalmente, tendo na literatura um viés significativo para essa construção.

\section{A LITERATURA ORAL NA HISTÓRIA DE D. TECEDERINHA}

Para alcançar o objetivo de entender a literatura oral e a relação entre a construção da identidade do contador de histórias e a memória que retém as narrativas ao longo do tempo, faz-se necessário conhecermos o conteúdo presente em tais narrativas, pois neste conteúdo podemos ver a complexidade a partir da qual são elaboradas. Salientamos que as histórias de Trancoso representam um aspecto fundamental da vida dos contadores e de seus ouvintes, pois encantam, divertem, fazem sonhar e refletir.

De acordo com a contadora, uma das atividades que as pessoas da comunidade realizavam para diversão era a contação de histórias, que ocorria regularmente durante a noite, quando se reuniam na calçada de algum morador. Ou, durante a colheita, ocasião na qual as pessoas se reuniam para ajudar uma as outras na debulha dos grãos, especialmente de feijão.

Nesse momento, quem sabia contar história se tornava o centro das atenções, sendo convidado para as debulhas, que geralmente contava com a presença de mais de um contador, como mostra a fala da contadora em uma das entrevistas para a pesquisa. Lembramos que nas falas, o C quer dizer contadora e o $\mathrm{P}$, pesquisadora.

C: Menina eu ia contar história em tudo que é canto. Era eu, C. B. C. nós tudo contava muita história de trancoso o povo gostava muito quando tinha disbuia (debulha) aí eu ia, lá pra B. pra M. pra todo canto.

P: E contava muita história?

C: Vixe Maria! Era a noite todinha o monte de feijão lá e todo mundo ao redor, as vez custava a terminar.

C: Essa que eu vou contar, contei muito, é a de Dona Tecederinha.

(ENTREVISTA/DEPOIMENTO) 
Nessa fala, podemos notar que a narradora se orgulha de seu talento de contar histórias e sabe que a arte de narrar se modificou, pois se refere ao passado para mostrar que lá as histórias eram um instrumento indispensável de lazer de sua comunidade, e através de sua voz participava da construção de uma prática cultural muito importante para seu povo.

Mostra ainda que a história de D. Tecederinha é uma das mais populares, informação que condiz com o que encontramos em nossas leituras, pois nos estudos de Cascudo (2004), podemos ver três versões dessa narrativa: "A princesa de Bambuluá; o veado de plumas; e o papagaio real". Em Lima (2005), a história aparece como o título de "o reino do vale verde" e em Rondelli (2003), se intitula de "a história do fim cantado". Nessas versões, podemos encontrar a composição da história de D. Tecederinha, com algumas variações, mas com o mesmo tema e aspectos idênticos no desenrolar do enredo.

Vamos conhecer a história de D. Tecederinha na versão da Contadora, na qual encontramos alguns elementos presentes na composição da história das três baginhas de feijão, como a presença do elemento três como número de vezes necessárias para atingir um objetivo. São três os objetos que ela manda fazer com o ouro que o príncipe deixava, a almofada de fazer renda, o pente e o espelho. Também são três os lugares onde D. Tecederinha procura até encontrar o Reino Jardim de Flores, e ainda três são as vezes que tenta falar com o príncipe Pássaro Verde, para poder conseguir o que deseja. Vejamos o enredo de Dona Tecederinha.

Era uma vez seis irmãs. Todas tinham um apelido. Elas eram chamadas de um olho, dois olhos, três olhos, quatro olhos, cinco olhos e a outra era Dona Tecederinha.

D. Tecederinha tecia e morava fora das irmãs. Numa casa sozinha. Lá ela trabalhava de tecedera. Quando era de noite vinha um pássaro pela janela, ela botava uma bacia d'água. Ele tomava banho e a bacia ficava cheia de ouro. Ele era um príncipe encantado, a coisa mais linda. 
Quando foi um dia, as irmãs deram fé (quer dizer perceberam). Um olho disse:

- Dona Tecederinha eu vou dormir mais tu.

- Pode vim.

Elas queriam descobrir o que era. D. Tecederinha à noite deu água de dormideira à irmã e ela não viu nada. Quando foi no outro dia, dois olhos disse:

- Hoje quem vai sou eu! Hoje eu vou e descubro. Quando foi de noite... D. Tecederinha deu a água de dormideira a ela, ele pegou no sono e também não viu nada. No outro dia três olhos foi e aconteceu da mesma forma. O príncipe disse:

- O que é isso D. Tecederinha? Tá havendo alguma coisa. Essas suas irmãs dormindo aqui não vai dar certo, porque elas vão fazer uma falsidade.

- Faz nada! Eu dou água de dormideira, elas não veem. Quando foi no outro dia, foi a vez de quatro olhos e aconteceu do mesmo modo. No outro dia, cinco olhos disse:

- Eu hoje vou e descubro! Eu sei o que é que ela tá fazendo. Tá dando água de dormideira a vocês. Por isso vocês não veem. Eu hoje quero vê se não descubro? E assim quando D. Tecederinha foi dá o copo de água de dormideira, ela foi botou por dentro do vestido e não pegou no sono de jeito nenhum. Quando o pássaro chegou, disse:

- Quem é que tá aqui hoje D. Tecederinha?

-É minha irmã, cinco olho.

- D. Tecederinha! Esse negócio não vai dar certo!

- Elas não veem porque eu dou água de dormideira a elas. Ele tomou banho e se transformou no príncipe, deixando a bacia cheia de ouro. Ela tava rica, já tinha mandado fazer muita coisa de ouro. E cinco olhos, que não dormiu, viu tudo. Quando foi no outro dia, cinco olhos disse em casa:

- Eu não disse que ia descobrir tudo. É um príncipe encantado. Ele vem como um pássaro passa pela janela, toma banho, se transforma em príncipe e deixa a bacia cheia de ouro.

- Ah! É assim? Por isso que ela tá rica. O que vamos fazer? Então botaram uma navalha envenenada na janela, e quando ele pousou cortou o pé.

- Ah! Malvada! Eu sabia que suas irmãs aqui ia dá falsidade.

- Mas pássaro verde não foi eu, foram minhas irmãs. Ele não quis tomar banho. Ela insistiu. Ele tomou, mas no lugar do ouro, a bacia ficou cheia de sangue. Ele disse: 
- Agora D. Tecederinha, você só me ver se for no reino jardim de flores. Se não for lá, não me vê mais nunca. Ela então mandou fazer uma almofada de ouro com os fusos tudo de ouro, um espelho e um pente de ouro. Arrumou todas as coisas dela e foi embora.

Andou, andou quando chegou em um casinha. Disse:

- Ô de casa!

- Ô de fora! Saiu uma velhinha, era a mãe da lua. Disse:

- Por aqui, minha filha?

- Minha velhinha, a senhora não dá notícia do reino jardim de flores?

- Dou não! Quem pode dar é a lua minha filha.

Se esconda de trás da porta, porque ela quando chega é muito valente.

Quando lá veio a lua:

- Aqui me cheira a sangue real! Aqui me cheira a sangue real!

- Minha filha! Você sabe que aqui não anda ninguém! Se acalma, minha filha! Botou água na bacia. A lua tomou banho. A velhinha disse:

- Minha filha! Você não dá notícia do reino jardim de flores?

- Dou não minha mãe. Por que minha mãe pergunta?

- Porque aqui tem uma pelegrina (peregrina) que vai pra lá.

- Só quem pode dá é o sol que anda muito. D. Tecedeirinha andou, andou, quando chegou noutra casinha.

- Ô de casa!

- Ô de fora! Saiu uma velhinha.

- Por aqui, minha filha?

- Minha velhinha, a senhora não dá notícia do reino jardim de flores?

- Dou não! Só quem pode dá é meu filho, o sol, mas ele chega tão ruim, tão valente quando chega aqui. Falta pouco é me matar. Mas não tem nada não. Se esconda aí de trás da porta.

Quando lá vinha o sol. Isso era uma quentura, parecendo que ia queimar tudo.

- Aqui me cheira a sangue real! Aqui me cheira a sangue real! 
- Meu filho! Você sabe que aqui não anda ninguém! Se acalma, meu filho! Botou água na bacia. O sol tomou banho. A velhinha disse:

- Meu filho você não dá notícia do reino jardim de flores?

- Dou não minha mãe. Por que minha mãe pergunta?

- Porque aqui tem uma pelegrina que vai pra lá.

- Só quem pode dá é o vento que anda muito. D. Tecedeirinha andou, andou, quando chegou noutra casinha.

- Ô de casa!

- Ô de fora! Saiu uma velhinha.

- Por aqui, minha filha? ...

- Minha velhinha, a senhora não dá notícia do reino jardim de flores?

- Dou não! Só quem pode dá é meu filho, o vento, mas ele chega tão valente, me torce, bota em cima da casa. Mas não tem nada não. Se esconda aí de trás da porta. Quando lá vinha o vento, no maior redemoinho do mundo.

- Aqui me cheira a sangue real! Aqui me cheira a sangue real!

- Meu filho! Você sabe que aqui não anda ninguém. Se acalma, meu filho! Botou água na bacia. 0 vento tomou banho. A velhinha disse:

- Meu filho! Você não dá notícia do reino jardim de flores?

- Dou, minha mãe! Cheguei de lá nesse instante. Porque minha mãe pergunta?

- Porque aqui tem uma pelegrina que vai pra lá.

- O príncipe vai casar daqui a três dias. Ele andava muito por fora, por lá levou um corte muito grande, quase morre. Nunca mais saiu de casa, agora vai casar. A pelegrina vai pra lá?

- É pra você levar ela e deixar lá. Ele disse:

- Pois pode montar aqui na minha cacunda e se agarre. Quando eu fizer bulandera (cambalhota) você se pegue. Ele fez a bulandera e ela se agarrou. Quando soltou, estavam embaixo de um pé de pau muito grande, onde tinha uma cacimba d'água. Era o reino jardim de flores. $O$ vento disse:

- Você fique aí que daqui a três dias é a festa, e você vai pra lá pra ajudar. O povo tava tudo carregando água pra festa. Então ela pediu um pote pra carregar água e ajudar na festa. E ficou por lá. Quando foi de noite, ela botou a almofada e foi fazer renda. Aí chegou a nega e disse: 
- Ô pelegrina! Ô coisa bonita! Só dava certo pra princesa minha senhora, que tá pra casar com príncipe meu senhor. Você vende?

- Diga a ela que eu vendo. A nega foi lá e a princesa disse:

- Diga a ela que mande. A nega disse. E D. Tecederinha respondeu:

- Eu não só vendo como dou, pra ela deixar eu passar a noite mais o moço dela. Aí foi a nega disse a princesa. E ela:

- Mais é muito bonito mesmo! Eu deixar essa pelegrina passar a noite mais meu noivo. A nega disse:

- Tem nada não. Nós damos água de dormideira a ele, e ele não vê nada.

- Pois diga a ela que mande. Aí ela mandou. Quando foi no outro dia D. Tecedeirinha tava se olhando no espelho de ouro, muito bonito. A nega chegou e disse:

- Ô pelegrina! Ô coisa bonita! Só dava certo pra princesa minha senhora, que tá pra casar com príncipe meu senhor. Você vende?

- Diga a ela que eu vendo. A nega foi lá e a princesa disse:

- Diga a ela que mande. A nega disse. E D. Tecederinha respondeu:

- Eu não só vendo como dou, pra ela deixar eu passar outra noite mais o moço dela. Aí foi a nega disse a princesa. E ela:

- Mais é muito bonito mesmo! Ela já passou uma noite, e quer passar outra? A nega disse:

- Tem nada não. Nós damos água de dormideira a ele, ele pega no sono e não vê ela.

- Pois diga a ela que mande. Aí ela mandou. D. Tecederinha passou a noite e nada.

No outro dia, ela tava penteando o cabelo com o pente de ouro, muito bonito. A nega chegou e disse:

- Ô pelegrina! Ô coisa bonita! Só dava certo pra princesa minha senhora, que tá pra casar com príncipe meu senhor. Você vende?

- Diga a ela que eu vendo. A nega foi lá e a princesa disse:

- Diga a ela que mande. A nega disse. E D. Tecederinha respondeu:

- Eu não só vendo como dou, pra ela deixar eu passar outra noite mais o moço dela. Aí foi a nega disse à princesa. E ela:

- Mais é muito bonito mesmo! Ela já passou duas noites, e quer passar outra? A nega disse:

- Tem nada não. Nós damos água de dormideira a ele, ele pega no sono e não vê ela. 
Acontece que neste mesmo dia, durante a tarde tinha um velho que veio conversar com o príncipe e disse:

- Senhor não deixou alguma amante por aí não? Por onde andou? Porque toda noite tem uma voz na sua porta, pedindo pra o senhor abrir e dizendo: Acorda Pássaro Verde! Tu não disseste que D. Tecederinha não vinha no reino Jardim de Flores. Hoje vim e tu dormindo! Acorda Pássaro Verde! Isso foi alguma amante que o senhor deixou por aí. Não lembra não? O príncipe então lembrou. E contou toda a história. O velho disse:

- Pois é água de dormideira que tão Ihe dando. Quando for the dá hoje, você bote por aqui por dentro da camisa.

Quando foi de noite que ela chegou e falou:

- Acorda Pássaro Verde! Ele abriu a porta, ela entrou. E passaram a noite conversando. Ele então disse:

-Você se arrume e vá, na hora do casamento. E ela assim fez.

Era um casamento em casa. E quando foi na hora de se casar, ele falou com o pai.

- Meu pai! Antes de me casar, eu quero falar um negócio com o senhor. E continuou:

- Olhe meu pai! O senhor tem uma mala da fechadura de ouro, aí o senhor perde a chave de ouro e manda fazer outra de prata. Hoje aparecendo a de ouro, com qual o senhor abrirá a mala?

- Ora meu filho! Com a de ouro, que já tava acostumado.

- Pois então a minha noiva é essa!

E aconteceu que ele casou com D. Tecederinha. E foi uma festa maior do mundo. E entrou por perna de pinto e saiu por perna de pato. Rei, meu senhor mandou dizer que você contasse quatro.

A história de D. Tecederinha apresenta um enredo no qual a heroína aparece logo de início como uma mulher forte e corajosa, que mora sozinha e se sustenta através do ofício de tecedeira, como fica claro no começo da narrativa, quando enfatiza que "D. Tecederinha tecia e morava fora das irmãs. Numa casa sozinha. Lá, ela trabalhava de tecedera." Em um contexto social rústico, dominado pelo masculino, como o de convívio da contadora, morar sozinha era um ato de bravura, que deu a D. Tecederinha a possibilidade de lutar por uma vida melhor. 
Essa luta, como muitas outras, aparece na busca pela felicidade. Para tanto, D. Tecederinha enfrenta vários obstáculos, a começar pelas próprias irmãs, que ao saberem de sua fortuna, planejam acabar com sua felicidade por causa da inveja. Sendo a inveja um tema bastante recorrente no conto popular, representa aqui um elemento de rompimento da ordem, trazendo a desordem que precisa ser reorganizada pela heroína. Esta precisa transpor um estado que Beth Rondelli (1993) chama de estado liminar, no qual o herói ou heroína transita entre um primeiro estado de ordem que é sua casa e a reorganização final, quando conquista o que está procurando.

Na reflexão social desse conto, vemos que em se tratando de uma heroína, é possível notarmos que suas ações se dão sempre no âmbito doméstico. Embora D. Tecederinha tenha se afastado do lar de sua família para morar sozinha, é preciso a presença masculina do príncipe para que possa sobreviver e melhorar de vida.

Além disso, os espaços por onde D. Tecederinha transita em busca do príncipe são, de certo modo, resguardados pela figura da velhinha, que a recebe no reino da lua, do sol e do vento, e a protege da fúria da lua, do sol e do vento, o que reforça o pensamento recorrente na sociedade, especialmente no âmbito rural tradicional, de que a mulher sempre precisa da ajuda de terceiros para poder conseguir algo.

Outro acontecimento no conto que revela esse aspecto é o modo pelo qual a heroína consegue se aproximar do príncipe. Para encontrá-lo é preciso realizar tarefas domésticas, como ajudar na preparação da festa, carregando água junto com os criados. Aqui, vemos que a ação da protagonista se restringe basicamente à execução de tarefas simples, sem muita complexidade ou heroísmo, no entanto, sua inteligência supera os obstáculos e faz com que possa reparar o erro cometido. 
Encontramos também, no enredo das histórias, alguns elementos que, por serem recorrentes, se tornam caracterizadores desse tipo de narrativa. Entre eles merece destaque a cacimba de água, que aparece sempre embaixo de uma grande árvore e o fato de carregar água para casa em um pote; e a velhinha, que aconselha e/ou ajuda o herói/heroína a resolver o conflito no qual se encontra.

Salientamos a presença da negra, que aparece novamente como empregada, e que exerce, nesse conto, o papel de intermediar a reaproximação de $D$. Tecederinha com o príncipe, embora o faça porque está tentando agradar a princesa, para quem trabalha. É clara sua atitude de submissão quando vê os objetos de ouro na mão de D. Tecederinha, a quem julga desmerecedora de tal joia, como podemos ver quando na fala que diz: “Ô pelegrina! Ô coisa bonita! Sá dava certo pra princesa minha senhora, que tá pra casar com príncipe meu senhor." Nesse trecho, fica evidente o papel delegado ao negro nas histórias de trancoso, pois em muitas das narrativas que ouvimos, tanto na coleta oficial dos dados, quanto em outros momentos, o negro ou a negra sempre aparece como empregado e/ou vilão.

$\mathrm{Na}$ composição da história, encontramos ainda algumas marcas da identidade cultural da contadora, que são deixadas através da linguagem, que torna visível os traços sertanejos, como o cumprimento ao chegar à casa de estranhos. Nesse momento, quem chega diz ô de casa! e quem está em casa responde ô de fora!. Esse é, ainda hoje, o modo mais comum de se apresentar e ser recebido nas comunidades mais afastadas dos grandes centros urbanos.

D. Tecederinha percorre o mundo em busca de seu príncipe, que se afasta devido a um erro que ela cometera e que necessita ser sanado. Foi o erro que levou a heroína a entrar em um mundo de desordem, na busca pela restauração de sua convivência social. Para tanto, é preciso superar os obstáculos, entre eles a água de dormideira, recurso usado por ela no início da trama para esconder sua real situação das irmãs, mas que reaparece no final para dificultar seu reencontro com o príncipe. 
Nesse momento, a heroína carece de ajuda, que chega na figura de um velhinho; ao ouvir os apelos de D. Tecederinha durante a noite, relata ao príncipe Pássaro Verde. Esse trecho da narrativa é bastante rico em elementos que colocam em pauta a relevância da memória na constituição da identidade. Ao lembrar-se do amor de D. Tecederinha, a partir da interferência da sabedoria de um velhinho, Pássaro Verde lembra, e é a lembrança que permite a reestruturação da ordem, tanto de sua vida, por poder retomar um amor que fora interrompido, como de D. Tecederinha, que se lançou ao desafio de reencontrá-lo, e assim recuperar a felicidade.

No desfecho da história, um recurso utilizado com frequência para o encerramento da trama nas histórias de Trancoso é uma pergunta feita pelo herói, geralmente dirigida ao rei, ou ao pai. "Olhe meu pai! O senhor tem uma mala da fechadura de ouro, aí o senhor perde a chave de ouro e manda fazer outra de prata. Hoje aparecendo a de ouro, com qual o senhor abrirá a mala?" e o pai responde: "ora meu filho! Com a de ouro que já estava acostumado!"

Ao ouvir a resposta do pai, Pássaro Verde pode então retomar a sua história com D. Tecederinha, através da recuperação representada na pergunta e resposta formulada, na qual a presença do pai como quem decide o destino dos filhos, e a quem o príncipe recorre para poder se casar com seu verdadeiro amor, que é D. Tecederinha, revela a legitimidade da heroína como sua verdadeira noiva. Rondelli mostra: “a recuperação, pela memória, dos episódios ocorridos num tempo passado permitirá que seja corrigida a ação presente que está, para o personagem narrador, sendo injusta." (1993, p. 110)

Desse modo, D. Tecederinha consegue retomar seu caminho através da recuperação do passado, que se revela no desfecho da narrativa, e é pela revelação do passado, que Pássaro Verde e D. Tecederinha podem então contar com a benção do pai, para se casarem e fazerem uma grande 
festa, muito comum no final das histórias de Trancoso, para mostrar que a ordem foi restabelecida, e que os personagens, depois de muito esforço, conseguiram conquistar aquilo que desejaram.

\section{CONCLUSÃO}

Vimos que o contador de histórias é aquele que detém na memória o conhecimento das histórias. Essa capacidade de guardar o enredo e ser ouvido pelos membros da comunidade faz com que construa sua identidade enquanto representatividade da comunidade em si, que o elege como sábio, capaz de orientar os seus pares na organização da vida diária.

Com isso, contar histórias se torna uma marca identitária, na qual está implícita uma relação de poder dentro da comunidade, uma vez que, como mostra Rondelli, "o contar histórias é, ao mesmo tempo, demonstração de sabedoria e discurso sobre o saber como instrumento de conquista do poder e riqueza" (1993, p. 46), mostrando que para o contador de histórias, a maior riqueza é mesmo a sabedoria adquirida com a experiência.

Partindo desse pressuposto, consideramos que os contos constituem uma criação coletiva, dado que cada contador introduz inevitavelmente pequenas alterações, que são as marcas da identidade cultural de quem conta, impregnada de sentimentos e visão de mundo, dando ao conto um caráter universal, por tratar de temas relacionados à condição humana, e ao mesmo tempo particular, por carregar as marcas individuais do contador que o reproduz.

\section{REFERÊNCIAS}

ALBERTI, Verena. Manual de história oral. 3. ed. Rio de Janeiro: FGV, 2005.

BOM MEIHY, José Carlos Sebe. Manual de história oral. 3. ed. São Paulo: Edições Loyola, 2000.

BOSI, Ecléa. Memória e sociedade: lembranças de Velhos. 11. ed. São Paulo: Companhia das Letras, 2007.

CANDIDO, Antonio. Literatura e sociedade: estudos de teoria e história literária. 8. ed. São Paulo: T. A . Queiroz, 2006. 
CASCUDO, Luís da Câmara. Contos tradicionais do Brasil. 13. Ed. São Paulo: Global, 2004.

HALBWACHS, Maurice. A memória coletiva. Trad. Laís Teles Benoir. São Paulo: Centauro, 2006.

LOZANO, Jorge Eduardo Aceves. "Práticas e estilos de pesquisa na história oral contemporânea." In.: AMADO, Janaina. e FERREIRA, Marieta de Morais. (coord.) Usos \& abusos da história oral. 8. ed. Rio de Janeiro: Editora FGV, 2006.

LIMA, Francisco Assis de Sousa. Conto popular e comunidade narrativa. 2. ed. São Paulo: Terceira Margem, 2005.

MENESES, Ulpiano Bezerra. "Identidade cultural e arqueologia." In: BOSI, Alfredo. Cultura brasileira: temas e situações. São Paulo: Ática, 2006.

POLLAK, Michael. "Memória, esquecimento, silêncio". In.: Estudos históricos, Rio de Janeiro, vol. 2, n. 3, 1989, p. 03-15.

. "Memória e identidade social." Estudos Históricos, Rio de Janeiro, vol. 5, n. 10, 1992, p. 200-212.

QUEIROZ, Maria Isaura Pereira de. Variações sobre a técnica de gravador no registro da informação viva. São Paulo: T.A. Queiroz, 1991.

RONDELLI, Beth. O narrado e o vivido: o processo comunicativo das narrativas orais entre pescadores do Maranhão. Rio de Janeiro: FUNARTE/IBAC, 1993.

XIDIEH, Oswaldo Elias. Narrativas populares: estórias de nosso Senhor Jesus Cristo e mais São Pedro andando pelo mundo. São Paulo: EDUSP; Belo Horizonte: Itatiaia, 1993.

Artigo recebido em: 31 de maio de 2018. Artigo aprovado em: 25 de agosto de 2018. 